\title{
Dearth of Hospitalist Investigators in Academic Medicine: A Call to Action
}

\author{
Evan Michael Shannon, MD, MPH',2*, Vineet Chopra, MD, MSc ${ }^{3}$, S Ryan Greysen, MD, MHS ${ }^{4,5}$, Shoshana J Herzig, MD, MPH²,6, \\ Sunil Kripalani, MD, MSc7,8, Kevin J O'Leary, MD, MS, Eduard E Vasilevskis, MD, MPH ${ }^{7}, 10$, Mark V Williams, MD ${ }^{11}$, \\ Stephanie K Mueller, MD, MPH ${ }^{1,2}$, Andrew D Auerbach, MD, MPH ${ }^{12}$, Jeffrey L Schnipper, MD, MPH ${ }^{1,2}$
}

\begin{abstract}
${ }^{1}$ Division of General Internal Medicine and Primary Care, Brigham and Women's Hospital, Boston, Massachusetts; ${ }^{2} \mathrm{Harvard}$ Medical School, Boston, Massachusetts; ${ }^{3}$ Division of Hospital Medicine, University of Michigan Medicine, Ann Arbor, Michigan; ${ }^{4}$ Section of Hospital Medicine, Division of General Internal Medicine, Perelman School of Medicine at the University of Pennsylvania, Philadelphia, Pennsylvania; ${ }^{5}$ Leonard Davis Institute of Health Economics, The Wharton School at the University of Pennsylvania, Philadelphia, Pennsylvania; ${ }^{6}$ Division of General Medicine, Beth Israel Deaconess Medical Center, Boston, Massachusetts; ${ }^{7}$ Section of Hospital Medicine, Division of General Internal Medicine and Public Health, Vanderbilt University, Nashville, Tennessee; ${ }^{8}$ Center for Clinical Quality and Implementation Research, Vanderbilt University, Nashville, Tennessee; ${ }^{9}$ Division of Hospital Medicine, Department of Medicine, Northwestern University Feinberg School of Medicine, Chicago, Illinois; ${ }^{10}$ Geriatric Research Education and Clinical Center, VA Tennessee Valley, Nashville, Tennessee; ${ }^{11}$ Center for Health Services Research, University of Kentucky, Lexington, Kentucky; 12Division of Hospital Medicine, University of California San Francisco, San Francisco, California.
\end{abstract}

$\mathrm{n}$ their report celebrating the increase in the number of hospitalists from a few hundred in the 1990s to more than 50,000 in 2016, Drs Robert Wachter and Lee Goldman also noted the stunted growth of productive hospital medicine research programs, which presents a challenge to academic credibility in hospital medicine. ${ }^{1}$ Given the substantial increase in the number of hospitalists over the past two decades, we surveyed adult academic hospital medicine groups to quantify the number of hospitalist clinician investigators and identify gaps in resources for researchers. The number of clinician investigators supported at academic medical centers (AMCs) remains disturbingly low despite the rapid growth of our specialty. Some programs also reported a lack of access to fundamental research services. We report selected results from our survey and provide recommendations to support and facilitate the development of clinician investigators in hospital medicine.

\section{DEARTH OF CLINICIAN INVESTIGATORS IN HOSPITAL MEDICINE}

We performed a survey of hospital medicine programs at AMCs in the United States through the Hospital Medicine Reengineering Network (HOMERuN), a hospital medicine research collaborative that facilitates and conducts multisite research studies. ${ }^{2}$ The purpose of this survey was to obtain a profile of adult academic hospital medicine groups. Surveys were distributed via email to directors and/or senior leaders of each hospital medicine group between January and August 2019. In the survey, a clinician investigator was defined as "faculty whose primary nonclinical focus is scientific papers and grant writing."

*Corresponding Author: Evan Michael Shannon, MD, MPH;

Email: eshannon2@bwh.harvard.edu; Twitter: @EMShan_MD.

Published online first February 17, 2021.

Find additional supporting information in the online version of this article.

Received: June 30, 2020; Revised: September 14, 2020;

Accepted: September 15, 2020

๑ 2021 Society of Hospital Medicine DOI 10.12788/jhm.3536
We received responses from 43 of the 86 invitees (50\%), each of whom represented a unique hospital medicine group; 41 of the representatives responded to the questions concerning available research services. Collectively, these 43 programs represented 2,503 hospitalists. There were 79 clinician investigators reported among all surveyed hospital medicine groups (3.1\% of all hospitalists). The median number of clinician investigators per hospital medicine group was 0 (range 0-12) (Appendix Figure 1), and 22 of 43 (51.2\%) hospital medicine groups reported having no clinician investigators. Two of the hospital medicine groups, however, reported having 12 clinician investigators at their respective institutions, comprising nearly one third of the total number of clinician investigators reported in the survey.

Many of the programs reported lack of access to resources such as research assistants (56.1\%) and dedicated research fellowships (53.7\%) (Appendix Figure 2). A number of groups reported a need for more support for various junior faculty development activities, including research mentoring (53.5\%), networking with other researchers (60.5\%), and access to clinical data from multiple sites (62.8\%).

One of the limitations of this survey was the manner in which the participating hospital medicine groups were chosen. Selection was based on groups affiliated with $\mathrm{HOMERuN}$; among those chosen were highly visible US AMCs, including $70 \%$ of the top 20 AMCs based on National Institutes of Health (NIH) funding. ${ }^{3}$ Therefore, our results likely overestimate the research presence of hospital medicine across all AMCs in the United States.

\section{LACK OF GROWTH OVER TIME: CONTEXTUALIZATION AND IMPLICATIONS}

Despite the substantial growth of hospital medicine over the past 2 decades, there has been no proportional increase in the number of hospitalist clinician investigators, with earlier surveys also demonstrating low numbers. ${ }^{4,5}$ Along with the survey by Chopra and colleagues published in 2019, ${ }^{6}$ our survey provides an additional contemporary appraisal of research activities for adult academic hospital medicine groups. In the survey 
by Chopra et al, only 54\% (15 of 28) of responding programs reported having any faculty with research as their major activity (ie, $>50 \%$ effort), and $3 \%$ of total faculty reported having funding for $>50 \%$ effort toward research. ${ }^{6}$ Our study expands upon these findings by providing more detailed data on the number of clinician investigators per hospital medicine group. Results of our survey showed a concentration of hospitalists within a small number of programs, which may have contributed to the observed lack of growth. We also expand on prior work by identifying a lack of resources and services to support hospitalist researchers.

The findings of our survey have important implications for the field of hospital medicine. Without a critical mass of hospitalist clinician investigators, the quality of research that addresses important questions in our field will suffer. It will also limit academic credibility of the field, as well as individual academic achievement; previous studies have consistently demonstrated that few hospitalists at AMCs achieve the rank of associate or full professor..$^{5-9}$

\section{POTENTIAL EXPLANATIONS}

\section{FOR LACK OF RESEARCH GROWTH}

The results of our study additionally offer possible explanations for the dearth of clinician investigators in hospital medicine. The limited access to research resources and fellowship training identified in our survey are critical domains that must be addressed in order to develop successful academic hospital medicine programs. ${ }^{4,6,8,10}$

Regarding dedicated hospital medicine research fellowships, there are only a handful across the country. The small number of existing research fellowships only have one or two fellows per year, and these positions often go unfilled because of a lack of applicants and lower salaries compared to full-time clinical positions. ${ }^{11}$ The lack of applicants for adult hospital medicine fellowship positions is also integrally linked to board certification requirements. Unlike pediatric hospital medicine where additional fellowship training is required to become board-certified, no such fellowship is required in adult hospital medicine. In pediatrics, this requirement has led to a rapid increase in the number of fellowships with scholarly work requirements (more than 60 fellowships, plus additional programs in development) and greater standardization among training experiences. ${ }^{12,13}$

The lack of fellowship applicants may also stem from the fact that many trainees are not aware of a potential career as a hospitalist clinician investigator due to limited exposure to this career at most AMCs. Our results revealed that nearly half of sites in our survey had zero clinician investigators, depriving trainees at these programs of role models and thus perpetuating a negative feedback loop. Lastly, although unfilled fellowship positions may indicate that demand is a larger problem than supply, it is also true that fellowship programs generate their own demand through recruitment efforts and the gradual establishment of a positive reputation.

Another potential explanation could relate to the development of hospital medicine in response to rising clinical demands at hospitals: compared with other medical specialties, AMCs may regard hospitalists as being clinicians first and academicians second. ${ }^{1,7,10}$ Also, hospitalists may be perceived as being beholden to hospitals and less engaged with their surrounding communities than other general medicine fields. With a small footprint in health equity research, academic hospital medicine may be less of a draw to generalists interested in pursuing this area of research. Further, there are very few underrepresented in medicine (URiM) hospital medicine research faculty. ${ }^{5}$

Another challenge to the career development of hospitalist researchers is the lack of available funding for the type of research typically conducted by hospitalists (eg, rigorous quality improvement implementation and evaluation, optimizing best evidence-based care delivery models, evaluation of patient safety in the hospital setting). As hospitalists tend to be system-level thinkers, this lack of funding may steer potential researchers away from externally funded research careers and into hospital operations and quality improvement positions. Also, unlike other medical specialties, there is no dedicated $\mathrm{NIH}$ funding source for hospital medicine research (eg, cardiology and the National Heart, Lung, and Blood Institute), placing hospitalists at a disadvantage in seeking funding compared to subspecialists.

\section{STRATEGIES TO ENHANCE RESEARCH PRESENCE}

We recommend several approaches-ones that should be pursued simultaneously - to increase the number of clinician investigators in hospital medicine. First, hospital medicine groups and their respective divisions, departments, and hospitals should allocate funding to support research resources; this includes investing in research assistants, data analysts, statisticians, and administrative support. Through the funding of such research infrastructure programs, AMCs could incentivize hospitalists to research best approaches to improve the value of healthcare delivery, ultimately leading to cost savings.

With $60 \%$ of respondents identifying the need for improved access to data across multiple sites, our survey also emphasizes the requirement for further collaboration among hospital medicine groups. Such collaboration could lead to highpowered observational studies and the evaluation of interventions across multiple sites, thus improving the generalizability of study findings.

The Society of Hospital Medicine (SHM) and its research committee can continue to expand the research footprint of hospital medicine. To date, the committee has achieved this by highlighting hospitalist research activity at the SHM Annual Conference Scientific Abstract and Poster Competition and developing a visiting professorship exchange program. In addition to these efforts, SHM could foster collaboration and networking between institutions, as well as take advantage of the current political push for expanded Medicare access by lobbying for robust funding for the Agency for Healthcare Research and Quality, which could provide more opportunities for hospitalists to study the effects of healthcare policy reform on the delivery of inpatient care. 
Another strategy to increase the number of hospitalist clinician investigators is to expand hospital medicine research fellowships and recruit trainees for these programs. Fellowships could be internally funded wherein a fellow's clinical productivity is used to offset the costs associated with obtaining advanced degrees. As an incentive to encourage applicants to temporarily forego a full-time clinical salary during fellowship, hospital medicine groups could offer expanded moonlighting opportunities and contribute to repayment of medical school loans. Hospital medicine groups should also advocate for $\mathrm{NIH}$-funded T32 or K12 training grants for hospital medicine. (There are, however, challenges with this approach because the number of T32 spots per NIH institute is usually fixed). The success of academic emergency medicine offers a precedent for such efforts: After the development of a K12 research training program in emergency medicine, the number of $\mathrm{NIH}$ sponsored principal investigators in this specialty increased by $40 \%$ in 6 years. ${ }^{14}$ Additionally, now that fellowships are required for the pediatric hospital medicine clinician investigators, it would be revealing to track the growth of this workforce..$^{12,13}$

Structured and formalized mentorship is an essential part of the development of clinician investigators in hospital medicine. ${ }^{47,8,10}$ One successful strategy for mentorship has been the partnering of hospital medicine groups with faculty of general internal medicine and other subspecialty divisions with robust research programs. ${ }^{7,8,15}$ In addition to developing sustainable mentorship programs, hospital medicine researchers must increase their visibility to trainees. Therefore, it is essential that the majority of academic hospital medicine groups not only hire clinician investigators but also invest in their development, rather than rely on the few programs that have several such faculty members. With this strategy, we could dramatically increase the number of hospitalist clinician investigators from a diverse background of training institutions.

SHM could also play a greater role in organizing events for

\section{References}

1. Wachter RM, Goldman L. Zero to 50,000 - The 20th anniversary of the hospitalist. N Engl J Med. 2016;375(11):1009-1011. https://doi.org/10.1056 /NEJMp1607958

2. Auerbach $A D$, Patel MS, Metlay JP, et al. The Hospital Medicine Reengineering Network (HOMERuN): a learning organization focused on improving hospital care. Acad Med. 2014;89(3):415-420. https://doi.org/10.1097 lacm.0000000000000139

3. Roskoski R Jr, Parslow TG. Ranking Tables of NIH funding to US medical schools in 2019. Blue Ridge Institute for Medical Research. Published 2020. Updated July 14, 2020. Accessed July 30, 2020. http://www.brimr.org/NIH Awards/2019/NIH_Awards_2019.htm

4. Reid MB, Misky GJ, Harrison RA, Sharpe B, Auerbach A, Glasheen JJ. Mentorship, productivity, and promotion among academic hospitalists. J Gen Intern Med. 2012;27(1):23-27. https://doi.org/10.1007/s11606-011-1892-5

5. Miller CS, Fogerty RL, Gann J, Bruti CP, Klein R; The Society of General Internal Medicine Membership Committee. The growth of hospitalists and the future of the society of general internal medicine: results from the 2014 membership survey. J Gen Intern Med. 2017;32(11):1179-1185. https://doi .org/10.1007/s11606-017-4126-7

6. Chopra V, Burden M, Jones CD, et al; Society of Hospital Medicine Research Committee. State of research in adult hospital medicine: results of a national survey. J Hosp Med. 2019;14(4):207-211. https://doi.org/10.12788/jhm.3136

7. Seymann GB, Southern W, Burger A, et al. Features of successful academic hospitalist programs: insights from the SCHOLAR (SuCcessful HOspitaLists in academics and research) project. J Hosp Med. 2016;11(10):708-713. https://doi.org/10.1002/jhm.2603 networking and mentoring for trainees and medical students interested in pursuing a career in hospital medicine research. It is also critically important that hospital medicine groups actively recruit, retain, and develop URiM hospital medicine research faculty in order to attract talented researchers and actively participate in the necessary effort to mitigate the inequities prevalent throughout our healthcare system.

\section{CONCLUSION}

Despite the growth of hospital medicine over the past decade, there remains a dearth of hospitalist clinician investigators at major AMCs in the United States. This may be due in part to lack of research resources and mentorship within hospital medicine groups. We believe that investment in these resources, expanded funding opportunities, mentorship development, research fellowship programs, and greater exposure of trainees to hospitalist researchers are solutions that should be strongly considered to develop hospitalist clinician investigators.

\section{Acknowledgments}

The authors thank HOMERuN executive committee members, including Grant Fletcher, MD, James Harrison, PhD, BSC, MPH, Peter K. Lindenauer, MD, Melissa Mattison, MD, David Meltzer, MD, PhD, Joshua Metlay, MD, PhD, Jennifer Myers, MD, Sumant Ranji, MD, Gregory Ruhnke, MD, MPH, Edmondo Robinson, MD, MBA, and Neil Sehgal, MPH PhD, for their assistance in developing the survey. They also thank Tiffany Lee, MA, for her project management assistance for HOMERuN.

Disclosures: Dr Schnipper was the recipient of an investigator-initiated grant from Mallinckrodt Pharmaceuticals regarding postsurgical opioid-related adverse drug events, outside of the submitted work. The other authors have nothing to disclose.

Funding: Dr Herzig reports receiving grant support from the Agency for Healthcare Research and Quality, outside of the submitted work. Dr Vasilevskis is the recipient of a National Institutes of Health grant, outside of the submitted work. $\mathrm{He}$ and Dr Chopra are US government employees and participated in creation of this paper as part of their official duties.

8. Harrison R, Hunter AJ, Sharpe B, Auerbach AD. Survey of US academic hospitalist leaders about mentorship and academic activities in hospitalist groups. J Hosp Med. 2011;6(1):5-9. https://doi.org/10.1002/jhm.836

9. Dang Do AN, Munchhof AM, Terry C, Emmett T, Kara A. Research and publication trends in hospital medicine. J Hosp Med. 2014;9(3):148-154. https ://doi.org/10.1002/jhm.2148

10. Sehgal NL, Sharpe BA, Auerbach AA, Wachter RM. Investing in the future: building an academic hospitalist faculty development program. J Hosp Med. 2011;6(3):161-166. https://doi.org/10.1002/jhm.845

11. Ranji SR, Rosenman DJ, Amin AN, Kripalani S. Hospital medicine fellowships: works in progress. Am J Med. 2006;119(1):72.e1-72.e7. https://doi .org/10.1016/j.amjmed.2005.07.061

12. Shah NH, Rhim HJ, Maniscalco J, Wilson K, Rassbach C. The current state of pediatric hospital medicine fellowships: a survey of program directors. J Hosp Med. 2016;11(5):324-328. https://doi.org/10.1002/jhm.2571

13. Jerardi KE, Fisher E, Rassbach C, et al; Council of Pediatric Hospital Medicine Fellowship Directors. Development of a curricular framework for pediatric hospital medicine fellowships. Pediatrics. 2017;140(1):e20170698. https://doi .org/10.1542/peds.2017-0698

14. Lewis RJ, Neumar RW. Research in emergency medicine: building the investigator pipeline. Ann Emerg Med. 2018;72(6):691-695. https://doi .org/10.1016/j.annemergmed.2018.10.019

15. Flanders SA, Kaufman SR, Nallamothu BK, Saint S. The University of Michigan Specialist-Hospitalist Allied Research Program: jumpstarting hospital medicine research. J Hosp Med. 2008;3(4):308-313. https://doi.org/10.1002 /jhm.342 